\title{
CHANGE OF SMALL STRAIN QUASI-ELASTIC DEFORMATION PROPERTIES DURING UNDRAINED CYCLIC TORSIONAL SHEAR AND TRIAXIAL TESTS OF TOYOURA SAND
}

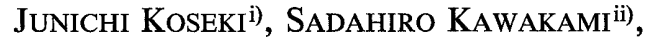 \\ Hiroshi NAGAYAMA ${ }^{\text {iii) }}$ and TAKESHI SATO ${ }^{\text {iv) }}$
}

\begin{abstract}
Undrained cyclic torsional shear and triaxial tests were performed on hollow cylindrical specimens of dense Toyoura sand, which were consolidated isotropically after preparation by air-pluviation and saturation. At several stress states, small strain quasi-elastic deformation properties were measured by applying very small amplitude cyclic torsional and vertical loads. During the liquefaction process, the observed degree of degradation of quasi-elastic shear modulus and vertical Young's modulus, was similar to that measured during isotropic consolidation. This suggests that the soil structure was damaged during the process of liquefaction. A larger extent of degradation was observed under triaxial extension or torsional shear than under triaxial compression condition. Such a change in the quasi-elastic deformation properties should be properly considered when analyzing the liquefaction process of sands based on elasto-plastic modeling. The behaviors observed during small amplitude cyclic vertical loading under undrained condition could be explained by considering inherent and stress state-induced anisotropy in the modeling of quasi-elastic deformation characteristics, and by correcting for the effects of membrane penetration. The latter correction was necessary, although the involved strain level was as small as $0.001 \%$.
\end{abstract}

Key words: liquefaction, sand, shear modulus, torsional shear, triaxial test, Young's modulus (IGC: D6/D7)

\section{INTRODUCTION}

In analyzing the liquefaction process of sands, their elasto-plastic deformation characteristics are essential. Under undrained condition, the contractive behavior of saturated sand due to cyclic shearing is balanced with rebound behavior due to reduction in the effective stress, resulting in the generation of excess pore water pressure. The former and latter behaviors are usually modeled in the framework of plasticity and elasticity, respectively. On the other hand, these elasto-plastic behaviors have not been fully revealed by laboratory tests, due to technical difficulties in accurately evaluating elastic and plastic strain components separately.

However, because of recent developments in the testing equipment, it has become possible to measure quasielastic deformation properties at a strain level as small as $0.001 \%$ or less, as summarized by Tatsuoka et al. (1999). For example, by using piezoceramic bender elements installed in the triaxial apparatus during large amplitude cyclic or monotonic vertical loading, Tanizawa et al. (1994) measured the shear wave velocities of solid cylindrical sand specimens, which were converted into shear moduli. By applying very small amplitude cyclic vertical loading during large amplitude cyclic vertical loading, Koseki et al. $(1998,1999)$ measured quasi-elastic vertical Young's moduli. It should be noted that no measurement has been made during large amplitude cyclic torsional shearing process, which may more closely simulate the change in the field stress conditions of a level ground subjected to horizontal earthquake motions, than to the cyclic vertical loading employed in the aforementioned studies. In the present study, referring to Tatsuoka et al. (1999), the term "quasi-elastic" will be employed in place of "elastic" in order to indicate the soil behavior in a small strain region over which the response is predominantly linearly elastic.

Given the above circumstances, a newly developed torsional shear testing apparatus was introduced. In applying torsional shear stresses to the top of a hollow cylin-

i) Associate Professor, Institute of Industrial Science, University of Tokyo, Roppongi 7-22-1, Minato-ku, Tokyo 106-8558.

ii) Engineer, Tottori Prefecture. (Formerly, Graduate Student, Department of Civil Engineering, University of Tokyo.)

iii) Engineer, Nippon Kokan Koji Co. (Formerly, Undergraduate Student, Department of Civil Engineering, College of Industrial Technology, Nihon University.)

iv) Research Associate, Institute of Industrial Science, University of Tokyo, Roppongi 7-22-1, Minato-ku, Tokyo 106-8558. Manuscript was received for review on April 21, 1999.

Written discussions on this paper should be submitted before January 1, 2001 to the Japanese Geotechnical Society, Sugayama Bldg. 4F, Kanda Awaji-cho 2-23, Chiyoda-ku, Tokyo 101-0063, Japan. Upon request the closing date may be extended one month. 
drical specimen, very small shear strains can be accurately controlled. At the same time, very small vertical strains can be controlled independently. Consequently, with such a configuration it is possible to measure the shear modulus and vertical Young's modulus of a single specimen in the quasi-elastic region during large amplitude cyclic torsional shear loading, large amplitude cyclic vertical loading, or both.

By using this apparatus, a series of large amplitude undrained torsional and triaxial tests was performed on isotropically consolidated specimens of dense Toyoura sand, while applying very small amplitude cyclic torsional and vertical loads at a number of stress states to measure the quasi-elastic deformation properties. Properties measured during the process of undrained shearing up to liquefaction were compared to those measured during the isotropic consolidation process. Some of the results obtained were also compared to those predicted theoretically based on the hypo-elastic cross-anisotropic modeling as proposed by Tatsuoka et al. (1999). Comparison of the results obtained in the present study was also made to those obtained earlier by Koseki et al. (1998) on solid cylindrical specimens.

\section{APPARATUS AND TESTING PROCEDURES}

A torsional shear testing apparatus was newly developed for the present study as schematically shown in Figs. 1 and 2. A hollow cylindrical specimen with an outer diameter of $20 \mathrm{~cm}$, inner diameter of $16 \mathrm{~cm}$ and a height of $30 \mathrm{~cm}$ was loaded in torsional and vertical directions independently. The vertical loading parts are driven by an AC servo motor which is connected to the loading shaft through a series of reduction-gears, two sets of electro-magnetic clutch, one eletro-magnetic brake and a ball screw with a pre-pressurized nut. Refer to Santucci de Magistris et al. (1999) for the detailed performances of this vertical loading system, employed for triaxial tests on solid cylindrical specimens. For the present apparatus, another set of a similar system was employed for the torsional loading parts (Fig. 2). This loading device is a displacement-controlled type from a mechanical point of view, while cyclic shear tests by keeping a specified stress amplitude can be also conducted by using a microcomputer which monitors the outputs from a load cell and controls the loading device accordingly.

The tested specimens were prepared by pluviating air dried Toyoura sand $\left(e_{\max }=0.961, e_{\min }=0.601\right)$ through air. After being saturated at a confining stress of $30 \mathrm{kPa}$ by a combination of vacuuming, flushing with de-aired water, and back-pressurizing (refer to Ampadu and Tatsuoka, 1993, for detailed procedures), they were isotropically consolidated to a confining stress of $\sigma_{v}^{\prime}=\sigma_{h}^{\prime}$ $=100 \mathrm{kPa}$, where $\sigma_{v}^{\prime}$ and $\sigma_{h}^{\prime}$ denote effective vertical (or axial) and horizontal (or radial) stresses, respectively. Note that the inner and outer cell pressures were kept equal throughout the tests so that the horizontal circumferential stress was always equal to the horizontal radial stress. The confining stress was then reduced to about 10
(1) Two-component load cell

(2) Displacement transducer for large vertical displacement

(3) Proximity transducer for small vertical displacement

(4) Screw shaft to adjust the vertical position of (3)

(5) Potentiometer for large rotational displacement

(6) Proximity transducer for small rotational displacement

(7) Screw to rotate the attachment of (6)

(8) High capacity differential pressure transducer for confining stress (9) Low capacity differential pressure transducer for volume change

(10) High capacity differential pressure transducer to adjust back pressure (not used in the present study)

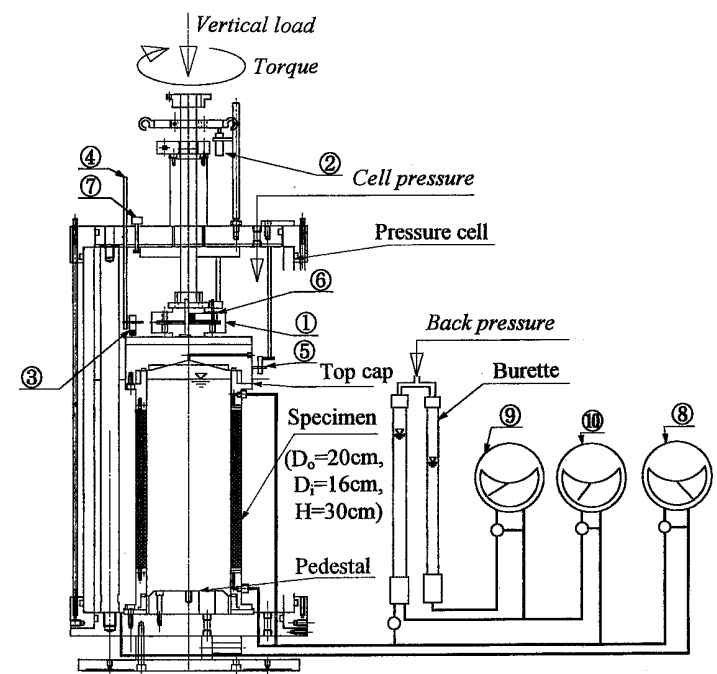

Fig. 1. Torsional and triaxial testing apparatus using hollow cylindrical specimens

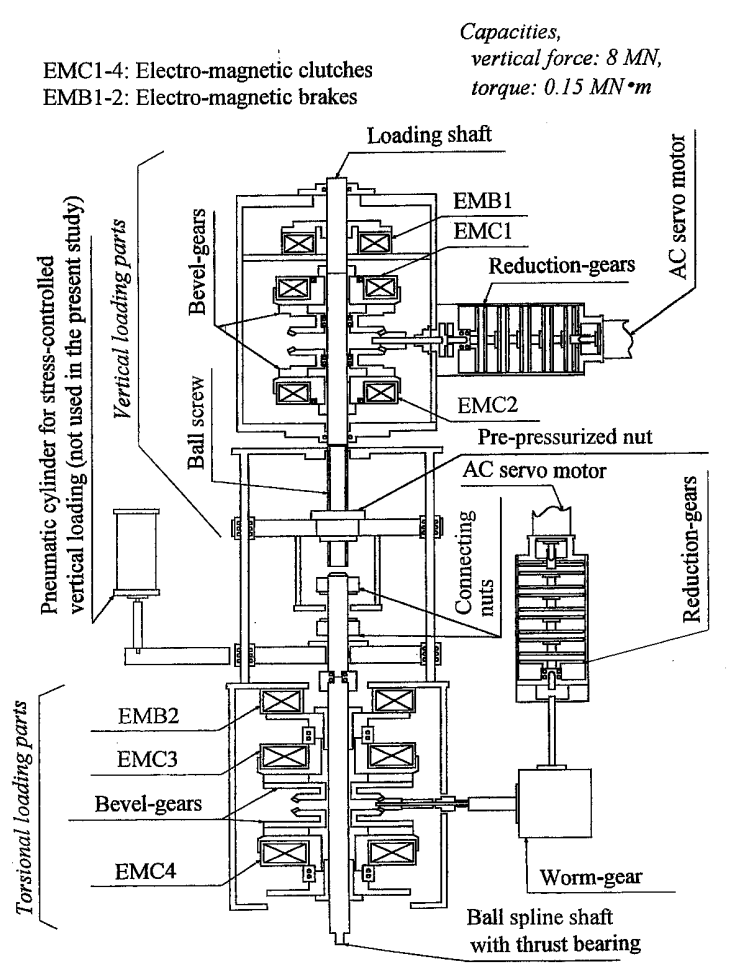

Fig. 2. Torsional and vertical loading device

$\mathrm{kPa}$ and restored to $100 \mathrm{kPa}$ in order to investigate behaviors at low confining stresses under isotropic stress states prior to liquefaction. 
During isotropic consolidation, after aging about 10 minutes at several stress levels, small cyclic torsional and vertical loads were applied independently, under both drained and undrained conditions with a single amplitude of about $0.0015 \%$ and $0.0010 \%$ for the shear strain $\gamma$ and the vertical strain $\varepsilon_{v}$, respectively. Typical results measured under drained condition are shown in Figs. 3 and 4. The drained shear modulus $G(=d \tau / d \gamma)$ and the drained vertical Young's modulus $E_{v}\left(=d q / d \varepsilon_{v}\right)$ were evaluated as shown in these figures, where $q$ is the deviator stress defined as $q=\sigma_{v}^{\prime}-\sigma_{h}^{\prime}$. The undrained moduli $G_{u}$ and $E_{v u}$ were evaluated in a similar manner based on the results conducted under undrained condition. Although the stress-strain relationships occasionally showed slight non-linearity as typically seen in Fig. 4, linear fitting on all the data measured during the small amplitude unloading and reloading was made in evaluating the quasi-elastic moduli during isotropic consolidation.

As schematically shown in Fig. 1, the torsional and vertical loads were measured with a two-component load cell that was set inside the pressure cell to eliminate the effects of friction between the loading shaft and the bearing house of the pressure cell. The confining stress was measured with a high capacity differential pressure transducer. Proximity transducers (gap sensors) were used to evaluate small amplitude shear and vertical strains by

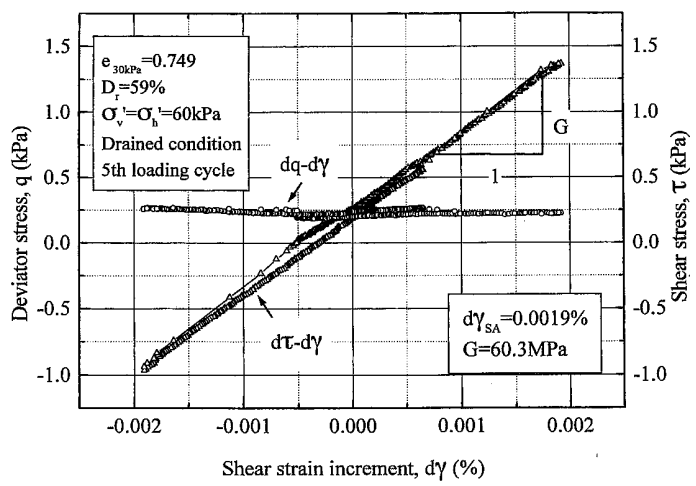

Fig. 3. Typical results during drained small cyclic torsional loading at isotropic stress state

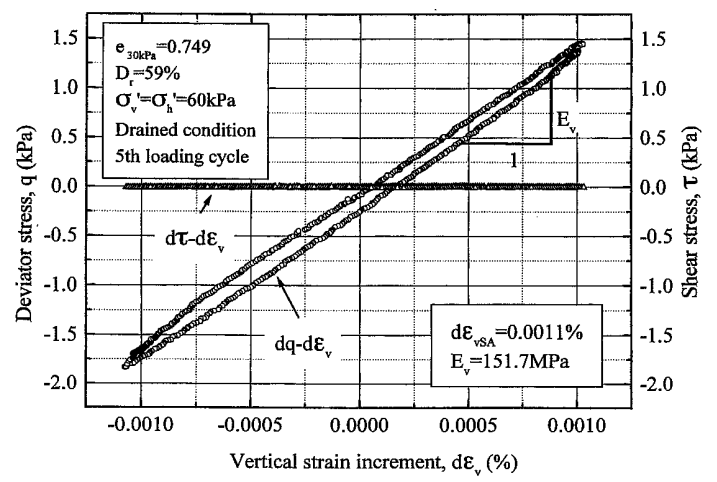

Fig. 4. Typical results during drained small cyclic vertical loading at isotropic stress state
Table 1. Test conditions

\begin{tabular}{|c|c|c|c|}
\hline Test name & $\begin{array}{c}\text { Void ratio, } \\
e_{30 \mathrm{kPa}} \text { at } \\
\sigma_{v}^{\prime}=\sigma_{h}^{\prime}=30 \mathrm{kPa}\end{array}$ & $\begin{array}{c}\text { Isotropic } \\
\text { consolidation }\end{array}$ & Shearing \\
\hline $\begin{array}{l}\text { Tests } 1 \\
\text { through } 4\end{array}$ & $\begin{array}{l}0.712 \sim \\
0.736\end{array}$ & \multicolumn{2}{|c|}{$\begin{array}{l}\text { (Preliminary tests to determine load- } \\
\text { ing conditions and to confirm con- } \\
\text { sistency with previous relevant tests, } \\
\text { not presented in this paper.) }\end{array}$} \\
\hline Test 5 & 0.749 & $\begin{aligned} \sigma_{v}^{\prime}= & \sigma_{h}^{\prime} \\
= & 30 \rightarrow 100 \rightarrow 10 \rightarrow 100 \\
& \rightarrow 10 \rightarrow 100 \mathrm{kPa}\end{aligned}$ & $\begin{array}{l}\text { Drained } \\
\text { monotonic } \\
\text { torsional }\end{array}$ \\
\hline Test 6 & 0.670 & $\begin{aligned} \sigma_{v}^{\prime}= & \sigma_{h}^{\prime} \\
= & 30 \rightarrow 100 \rightarrow 10 \\
& \rightarrow 100 \mathrm{kPa}\end{aligned}$ & $\begin{array}{l}\text { Undrained } \\
\text { cyclic } \\
\text { triaxial }\end{array}$ \\
\hline Test 7 & 0.712 & Same as Test 6 & $\begin{array}{l}\text { Undrained } \\
\text { cyclic } \\
\text { torsional }\end{array}$ \\
\hline
\end{tabular}

measuring the rotational and vertical displacements of the top cap, while a potentiometer and an external displacement transducer were employed to evaluate large amplitude shear and vertical strains, respectively. A low capacity differential pressure transducer was used to evaluate volumetric strains by measuring the change of water head in a burette connected to the drainage from the specimen.

From an isotropic stress state with $\sigma_{v}^{\prime}=\sigma_{h}^{\prime}=100 \mathrm{kPa}$ and a back pressure of $200 \mathrm{kPa}$, a cyclic torsional load with a single amplitude of $40 \mathrm{kPa}$ for the shear stress $\tau$ was applied under undrained condition on one specimen in Test 7 , while maintaining a constant vertical stress that was corrected for the change in the cross-sectional area of the specimen. On another specimen in Test 6 , a cyclic vertical load was applied under undrained condition with a single amplitude of $80 \mathrm{kPa}$ for the deviator stress $q=$ $\sigma_{v}^{\prime}-\sigma_{h}^{\prime}$, while keeping the torsional load at zero. Refer to Table 1 for a summary of test conditions, including other test cases to be mentioned later. In Tests 6 and 7, when the prescribed stress states were attained, very small amplitude unload and reload cycles with strain amplitudes similar to those employed during isotropic consolidation were applied in the torsional and vertical directions independently, by maintaining the undrained condition and without aging. The stress-strain relationship and the effective stress path in these tests are shown in Figs. 5 and 6 , where the effective stress path was plotted in terms of the effective mean principal stress $p^{\prime}$ defined as $p^{\prime}=\left(\sigma_{v}^{\prime}+\right.$ $\left.2 \sigma_{h}^{\prime}\right) / 3$. Typical results from small cyclic loading are also shown in these figures, based on which the undrained shear modulus $G_{u}$ and the undrained vertical Young's modulus $E_{v u}$ during shearing were evaluated. It should be noted that the relationships between $\tau$ and $\gamma$ measured during the small amplitude torsional unloading showed unstable behaviors such as the stepwise or no-linear changes shown in Figs. 5a and 6a. These behaviors are due possibly to the effects of system-compliance and/or back-lash of the torsional loading system associated with the condition of $\tau$ not equal to zero during shearing. The 

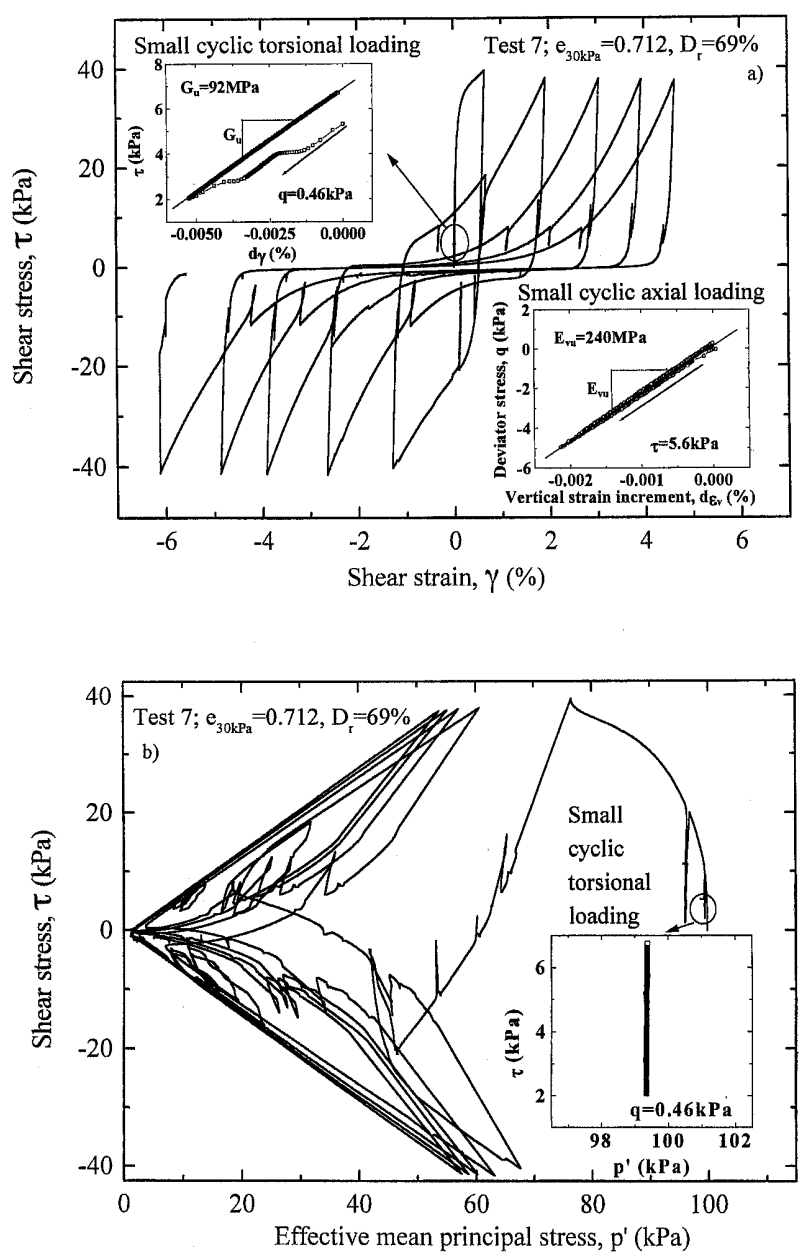

Fig. 5. Results of Test 7 during large amplitude undrained cyclic torsional shearing: a) stress-strain relationship, b) effective stress path

relatively stable behaviors which were measured during the small amplitude torsional reloading were, therefore, employed to evaluate the $G_{u}$ values. Further modifications of the apparatus are required on this issue. On the other hand, the $E_{u}$ values were evaluated by linear fitting all the data measured during the small amplitude axial unloading and reloading, as mentioned previously on the data measured during isotropic consolidation.

It is to be noted that in Test 5, torsional loads were monotonically increased under drained condition, which will not be reported in the present paper except for the vertical Young's modulus measured during isotropic consolidation (Fig. 7). Note also that results from Tests 1 and 4 will not be reported in the present paper, since these tests were conducted preliminarily in order to determine the loading condition as employed in Tests 5 through 7 and to confirm the consistency of the results with those of previous relevant tests (Table 1).

\section{RESULTS AND DISCUSSIONS}

Quasi-elastic Deformation Properties during Isotropic Consolidation

Drained vertical Young's modulus $E_{v}$ measured during
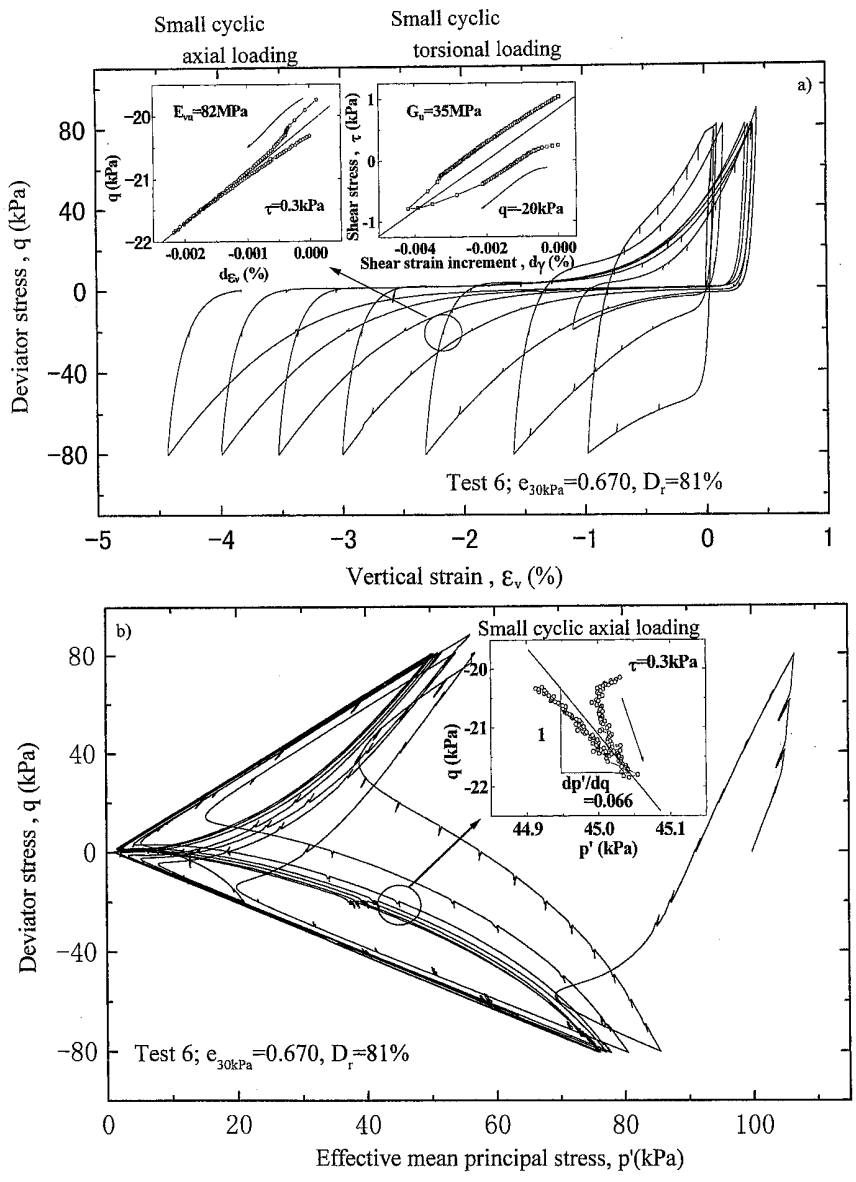

Fig. 6. Results of Test 6 during large amplitude undrained cyclic triaxial shearing: a) stress-strain relationship, b) effective stress path

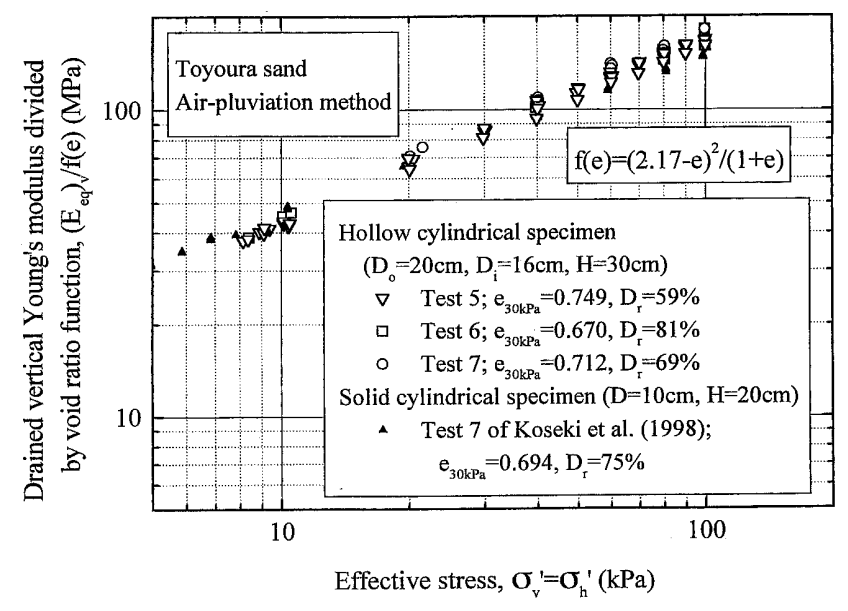

Fig. 7. Drained Young's modulus versus confining stress at isotropic stress state

isotropic consolidation was corrected for the change in the void ratio $e$, by dividing it with the void ratio function $f(e)=(2.17-e)^{2} /(1+e)$ proposed by Hardin and Richart (1963). The relationship between the values of $E_{v}$ $/ f(e)$ and the confining stress is presented in Fig. 7. By making the above correction, results from Tests 5 through 7 conducted at different values of $e$ in the range 


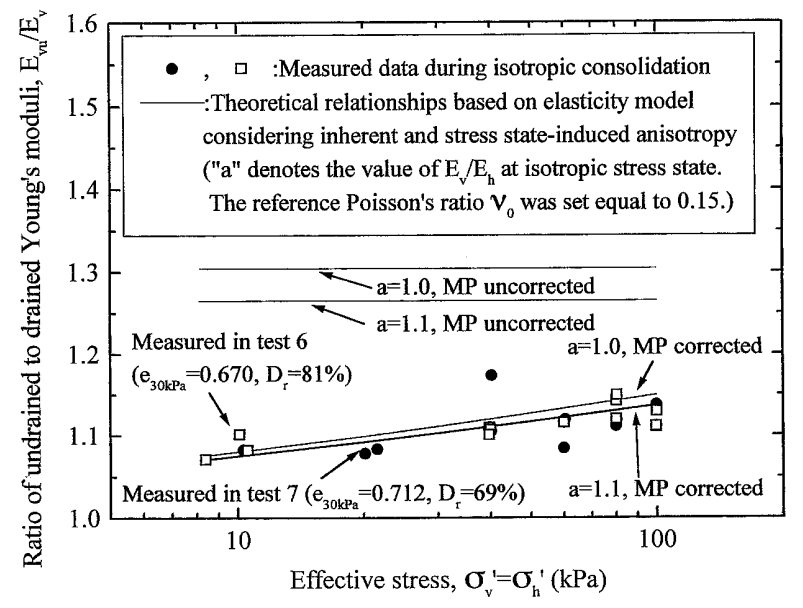

Fig. 8. Ratio of undrained to drained Young's moduli at isotropic stress state

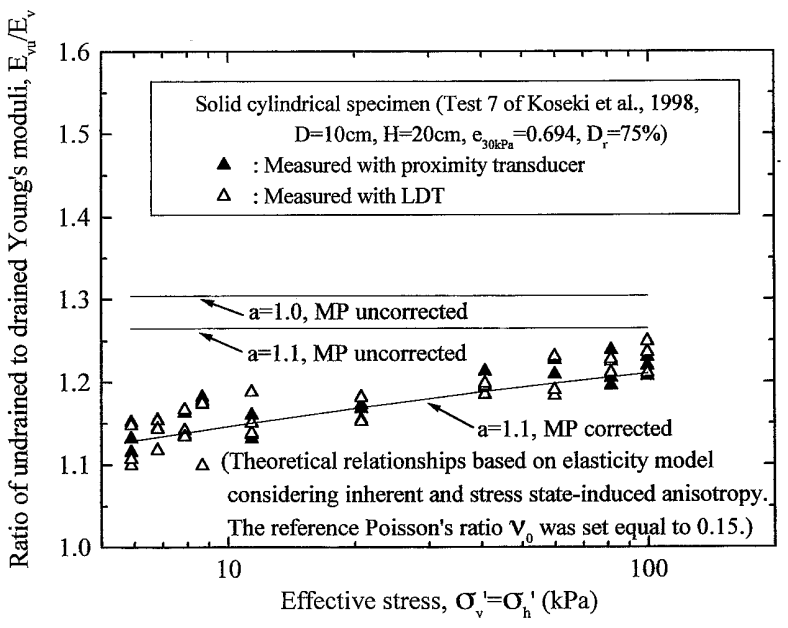

Fig. 9. Ratio of undrained to drained Young's moduli at isotropic stress state obtained on solid cylindrical specimen (Koseki et al., 1998)

between 0.67 and 0.75 became almost identical. They were also similar to the results from triaxial tests using solid cylindrical specimen with a diameter of $10 \mathrm{~cm}$ and a height of $20 \mathrm{~cm}$ reported earlier by Koseki et al. (1998). The latter similarity demonstrates that the vertical Young's modulus can be evaluated by conducting small vertical loading on hollow cylindrical specimens in the same way as on solid cylindrical specimens.

Measured ratios of the undrained vertical Young's modulus to the drained one, $E_{v u} / E_{v}$, are plotted versus the confining stress in Fig. 8. Theoretical relationships obtained by using Eq. (8) in the Appendix, based on the assumption of a cross-anisotropic elastic behavior, are also shown in the figure. Refer to the Appendix for the details of the theory. It can be seen that the observed behavior is reasonably simulated by the theory with the correction for the effects of membrane penetration (hereafter denoted as MP). Although the involved strain level was as small as $0.001 \%$, correction for the effects of MP was necessary. Similar behavior has been observed in solid

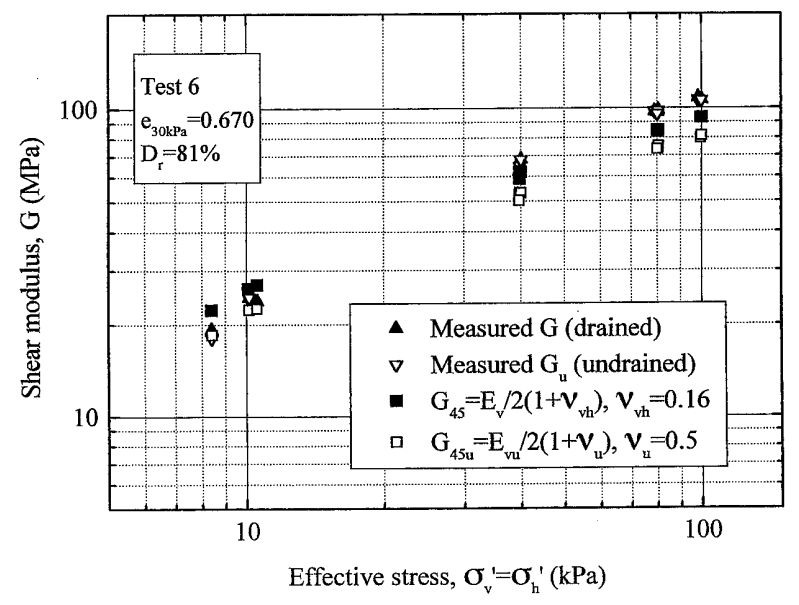

Fig. 10. Drained and undrained shear moduli versus confining stress at isotropic stress state in Test 6

cylindrical specimens by Koseki et al. (1998) as shown in Fig. 9. As seen from these figures, the effects of MP were larger on hollow cylindrical specimens than on solid ones, because of the use of an inner membrane in the former. The importance of correcting for the effects of MP in undrained small amplitude cyclic triaxial tests has been demonstrated by Yamashita et al. (1996).

The drained and undrained shear moduli, $G$ and $G_{u}$, measured in Test 6 are plotted versus the confining stress in Fig. 10. These values were almost the same irrespective of the drainage condition. This figure also shows values of $G_{45}$ and $G_{45 u}$, based on the relationships between the shear stress and the shear strain mobilized on a plane inclined by 45 degrees from the horizontal plane, which were converted from $E_{v}$ and $E_{v u}$ by assuming the values of the drained and undrained Poisson's ratios, $v_{v h}$ and $v_{u}$ to be 0.16 and 0.5 , respectively. Note that the value of $v_{v h}$ was set with reference to experimental data for the airpluviated specimen of Toyoura sand under isotropic stress state reported by Hoque and Tatsuoka (1998), while that of $v_{u}$ was set considering no volume change during undrained loading. From Fig. 10, it is clear that the values of $G_{45}$ were generally similar to those of $G$ and $G_{u}$. This similarity may suggest that the effects of inherent anisotropy on shear moduli are relatively small. They are likely to be comparable to those on the Young's modulus for the air-pluviated Toyoura sand as reported by Hoque and Tatsuoka (1998), where the ratio of the vertical to horizontal Young's moduli was about 1.1 under isotropic stress states. On the other hand, the values of $G_{45 u}$ were generally smaller than the other values. This discrepancy may be partly caused by the effects of MP that resulted in underestimation of $E_{v u}$ when these effects were neglected, as seen from Fig. 8 and as has been pointed out by Yamashita et al. (1996). Similar trends of behavior were also obtained in Tests 5 and 7.

\section{Young's Moduli during Large Amplitude Undrained Cyclic Shearing}

Values of $\boldsymbol{E}_{v u}^{\prime}$ measured at several stress states during liq- 


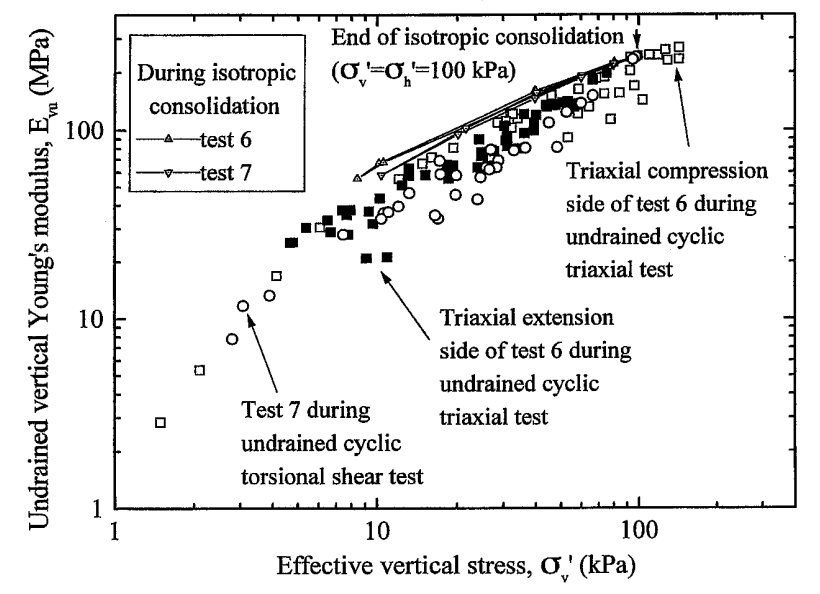

Fig. 11. Undrained Young's modulus versus effective vertical stress

uefaction by large amplitude undrained cyclic shearing in Tests 6 and 7 are plotted versus $\sigma_{v}^{\prime}$ and compared with those measured during isotropic consolidation in Fig. 11. It can be seen that the $E_{v u}$ values measured during liquefaction process were smaller than those during isotropic consolidation measured at the same $\sigma_{v}^{\prime}$. This degradation suggests that the soil structure is damaged during liquefaction. It should be noted, however, that the $\sigma_{h}^{\prime}$ values during the liquefaction process in Test 6 were not always equal to $\sigma_{v}^{\prime}$, while those in Test 7 were kept equal to $\sigma_{v}^{\prime}$. The former stress states are different from those during isotropic consolidation, and this may result in a different ratio of $E_{v u}$ to $E_{v}$. In the theory assuming a cross-anisotropic elastic body, the ratio changes depending on the values of $R=\sigma_{v}^{\prime} / \sigma_{h}^{\prime}$, as seen from Eqs. (8) and (9) in the Appendix.

To correct for the above difference, by using Eqs. (8) and (9) under the condition as given in the Appendix (i.e., $a=1.1$ and $v_{0}=0.15$ with MP correction, where $a$ is a parameter representing the degree of inherent anisotropy, and $v_{0}$ is a drained Poisson's ratio under a stress state when the material exhibits isotropic behavior, which is slightly different from the aforementioned value of $v_{v h}$ defined under isotropic stress state), values of $E_{v}$ during liquefaction process in both tests were estimated from the above results and compared with those measured during isotropic consolidation in Fig. 12. It is seen that the estimated $E_{v}$ values during liquefaction process were smaller than those during isotropic consolidation at the same $\sigma_{v}^{\prime}$. It should be noted that the difference in the $E_{v}$ values between these processes may be over-estimated to a certain extent in the present study, because the $E_{v}$ values were measured after aging for 30 minutes during isotropic consolidation, while no aging effects were involved during the liquefaction process. In relation to this, Hoque (1996) has reported that the $E_{v}$ values of medium dense to dense Toyoura sand subjected to cyclic prestraining recovered with time partially from reduced values.

When Figs. 11 and 12 are compared in detail, it is seen that the deviation among the values of Young's modulus

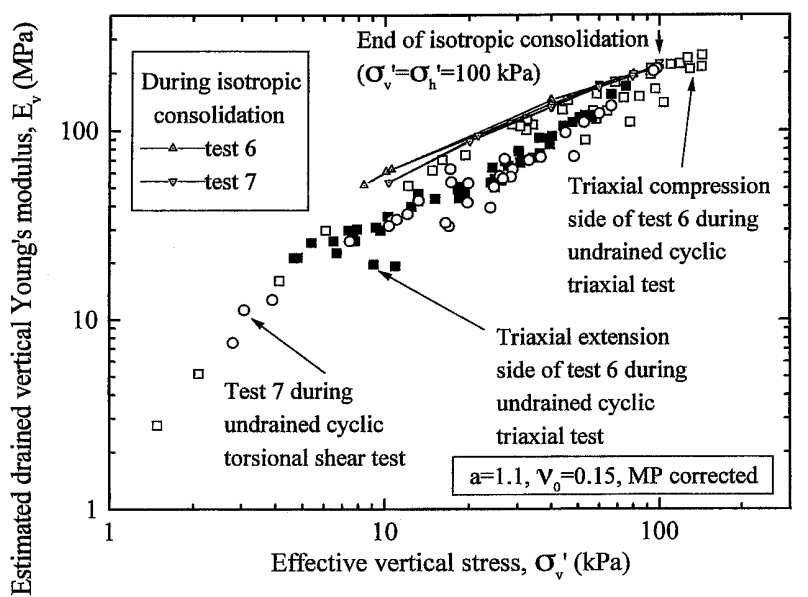

Fig. 12. Estimated drained Young's modulus versus effective vertical stress

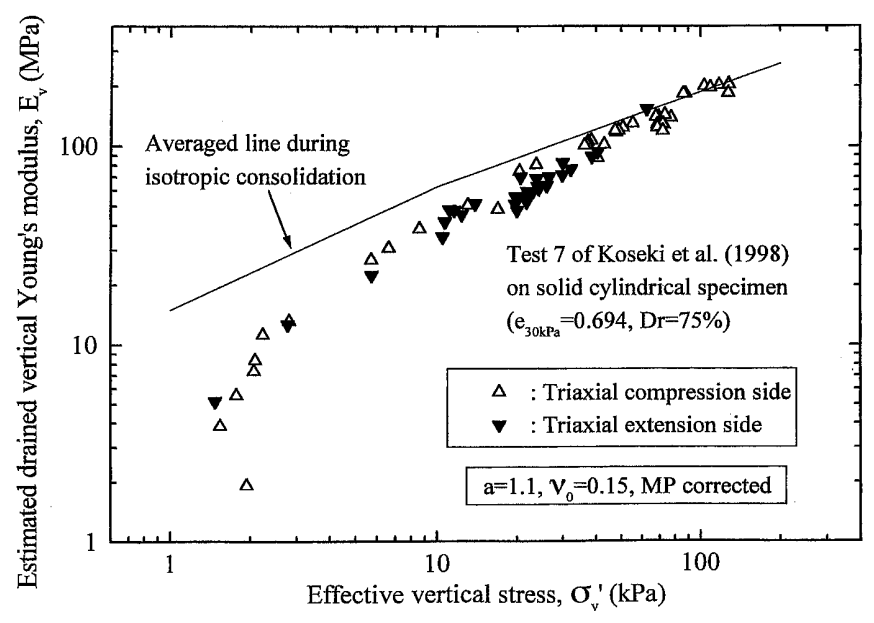

Fig. 13. Estimated drained Young's modulus versus effective vertical stress obtained on solid cylindrical specimen (Koseki et al., 1998)

under triaxial extension condition $(R<1)$ in Test 6 could be reduced by converting $E_{v u}$ to $E_{v}$ considering the effects of inherent and stress state-induced anisotropy and those of MP. On the other hand, possible reduction in the deviation under triaxial compression condition $(R>1)$ was not clearly observed.

It can also be seen from Fig. 12 that in Test 6, the estimated $E_{v}$ values under triaxial extension condition were generally smaller than those under triaxial compression condition. This suggests that the extent of damage to the soil structure during the liquefaction process by applying cyclic vertical load is larger under triaxial extension condition than under triaxial compression condition. The same trend of behavior has been observed in the estimated drained vertical Young's moduli of solid cylindrical specimens by Koseki et al. (1998), as shown in Fig. 13. A similar trend of behavior could also be seen in Fig. 10 of Tanizawa et al. (1994) on the shear moduli measured with bender elements.

To compare the extent of degradation between Tests 6 and 7, the $E_{v}$ values during cyclic loading $\left(E_{v, c y c}\right)$ normal- 


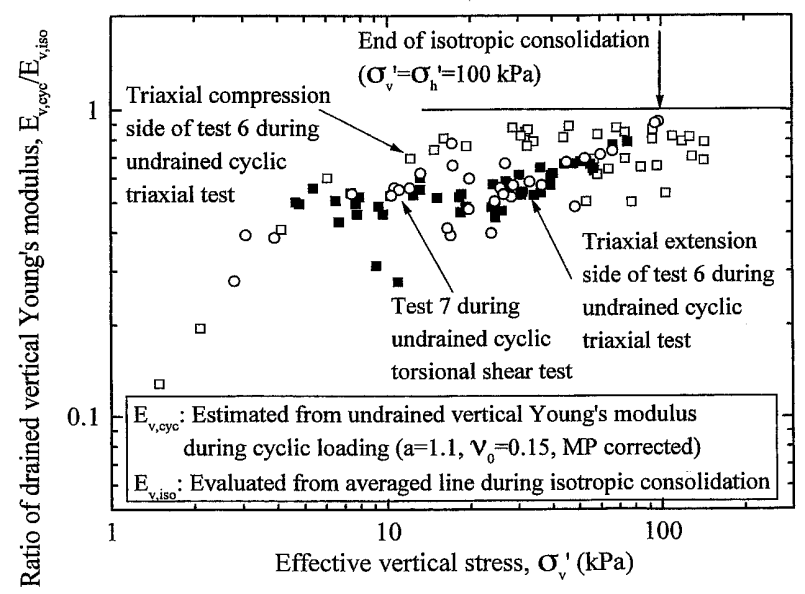

Fig. 14. Degradation of drained Young's modulus during liquefaction

ized by those evaluated at the same $\sigma_{v}^{\prime}$ from an averaged relationship for each test measured during isotropic consolidation $\left(E_{v, \text { iso }}\right)$ are plotted versus $\sigma_{v}^{\prime}$ in Fig. 14. It is evident that in Test 7, the reduction in the $E_{v}$ values during liquefaction process by applying cyclic torsional loads was comparable to that under triaxial extension condition in Test 6.

\section{Shear Moduli during Large Amplitude Undrained Cyclic Shearing}

Values of $G_{u}$ measured at several stress states during liquefaction by large amplitude undrained cyclic shearing in Tests 6 and 7 are plotted versus the effective mean stress $\sigma_{m}^{\prime}=\left(\sigma_{v}^{\prime}+\sigma_{h}^{\prime}\right) / 2$ and compared with those measured during isotropic consolidation in Fig. 15. It can be seen that, when compared at the same $\sigma_{m}^{\prime}$, the $G_{u}$ values during liquefaction process in both tests became smaller than those during isotropic consolidation.

Based on these results, the ratio of $G_{u}$ values during liquefaction $\left(G_{u, c y c}\right)$ to those during isotropic consolidation $\left(G_{u, i s o}\right)$, which were evaluated at the same $\sigma_{m}^{\prime}$, are plotted versus $\sigma_{m}^{\prime}$ in Fig. 16 . The extent of degradation in the $G_{u}$ values was in general similar to that in the $E_{v}$ values as shown in Fig. 14, and effects of the different stress states (i.e., triaxial compression and extension conditions in Test 6 and condition of $\sigma_{v}^{\prime}=\sigma_{h}^{\prime}$ in Test 7) on the $G_{u}$ values were also qualitatively similar to those previously mentioned on the $E_{v}$ values. These behaviors suggest that the damage to the soil structure during liquefaction occurs in a similar manner with respect to the Young's modulus in the vertical direction and the shear modulus defined on vertical and horizontal planes.

The different extent of degradation in the quasi-elastic properties that depends on the stress state should be properly considered in analyzing the liquefaction process based on elasto-plastic modeling. For example, if the amount of excess pore water pressure is evaluated by balancing the contractive behavior of saturated sand due to cyclic shearing with the rebound behavior due to reduction in the effective stress, the bulk modulus of sand dur-

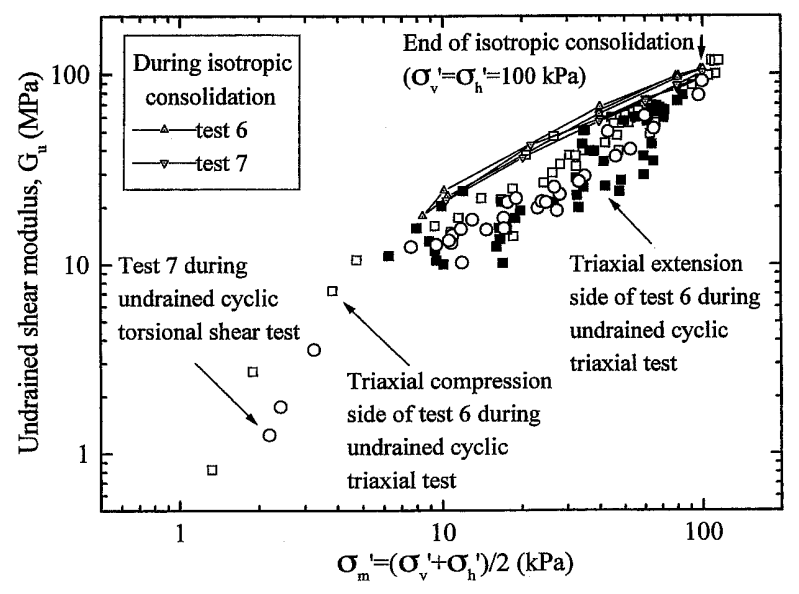

Fig. 15. Undrained shear modulus versus effective mean stress, $\sigma_{m}^{\prime}=\left(\sigma_{v}^{\prime}+\sigma_{h}^{\prime}\right) / 2$

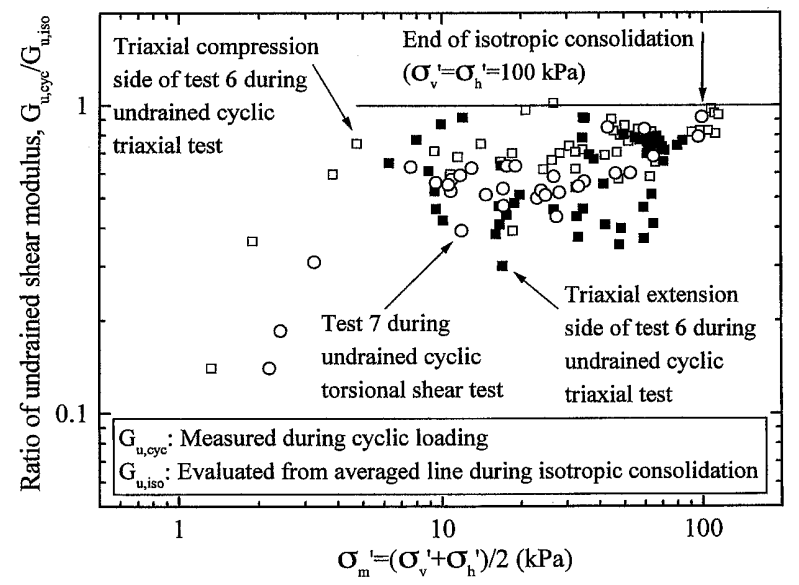

Fig. 16. Degradation of undrained shear modulus during liquefaction

ing rebounding that is usually assumed as "elastic" in a broad sense will directly affect the calculated result. Since such "elastic" behavior should be linked with the quasielastic behavior, degradation in the quasi-elastic properties should be properly considered as well.

Tatsuoka and Kohata (1995), who proposed the formulation of the quasi-elastic properties adopted in the present study as summarized in the Appendix, maintain that these properties may deteriorate by shear deformation. They introduced a damage function to correct for such deterioration based on parameter $S L=q / q_{\max }$, where $q_{\max }$ denotes the maximum deviator stress obtained from monotonic loading. On the other hand, deterioration of the quasi-elastic properties during cyclic loading has not been well understood. In the present study, therefore, a comparison between the observed behavior and the one predicted using the elastic formulation proposed by Tatsuoka and Kohata (1995) without considering the deterioration was made to reveal the effect of the deterioration based on the difference between these behaviors.

For reference, the $G_{u}$ values are plotted versus the effective mean principal stress $p^{\prime}=\left(\sigma_{v}^{\prime}+2 \sigma_{h}^{\prime}\right) / 3$ in Fig. 17, 


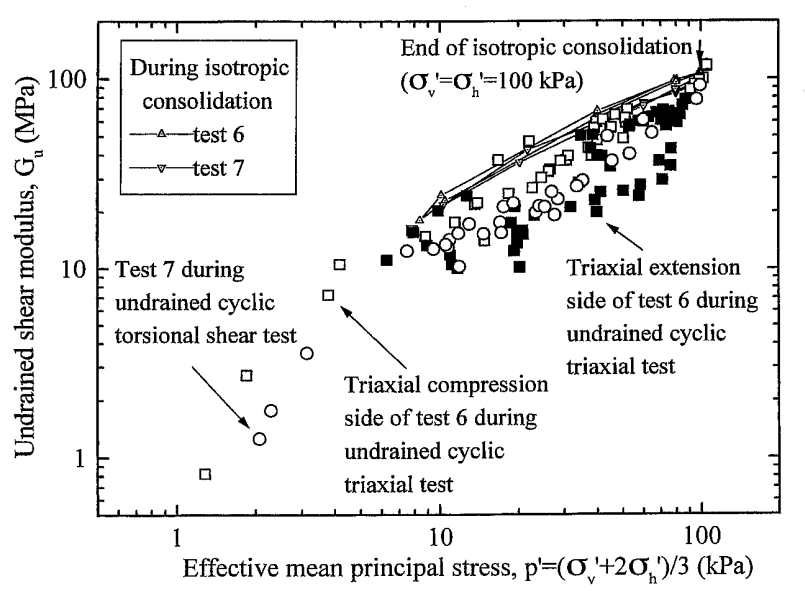

Fig. 17. Undrained shear modulus versus effective mean principal stress, $p^{\prime}=\left(\sigma_{v}^{\prime}+2 \sigma_{h}^{\prime}\right) / 3$

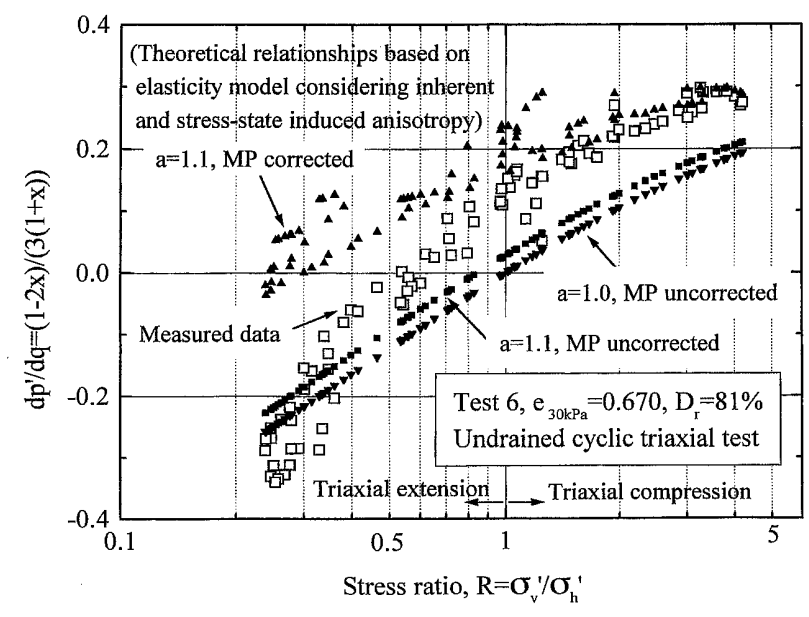

Fig. 18. Direction of effective stress path during undrained small cyclic vertical loading in Test 6

since it has not yet been well established whether shear moduli should be modeled in principle as a function of $\sigma_{m}^{\prime}, p^{\prime}$, or other stress parameters. It is evident from Figs. 15 and 17 that the above-mentioned trend of behavior did not change largely, while degradation under triaxial extension condition was slightly enhanced by comparing the $G_{u}$ values at the same $p^{\prime}$.

\section{Effective Stress Path during Undrained Small Vertical Loading in Test 6}

In Fig. 18, values of $d p^{\prime} / d q$ measured during undrained small cyclic vertical loading in Test 6 , which denotes the average direction of the effective stress path as typically shown in Fig. 6b, are plotted versus the current stress ratio $R\left(=\sigma_{v}^{\prime} / \sigma_{h}^{\prime}\right)$ and compared to theoretical values calculated by using Eqs. (9) and (10) in the Appendix. It can be seen that, under the same conditions as employed in the previous calculation (i.e., $a=1.1$ and $v_{0}=0.15$ with MP correction), the measured relationship could be reasonably simulated by the theory under triaxial compression condition, while under triaxial extension

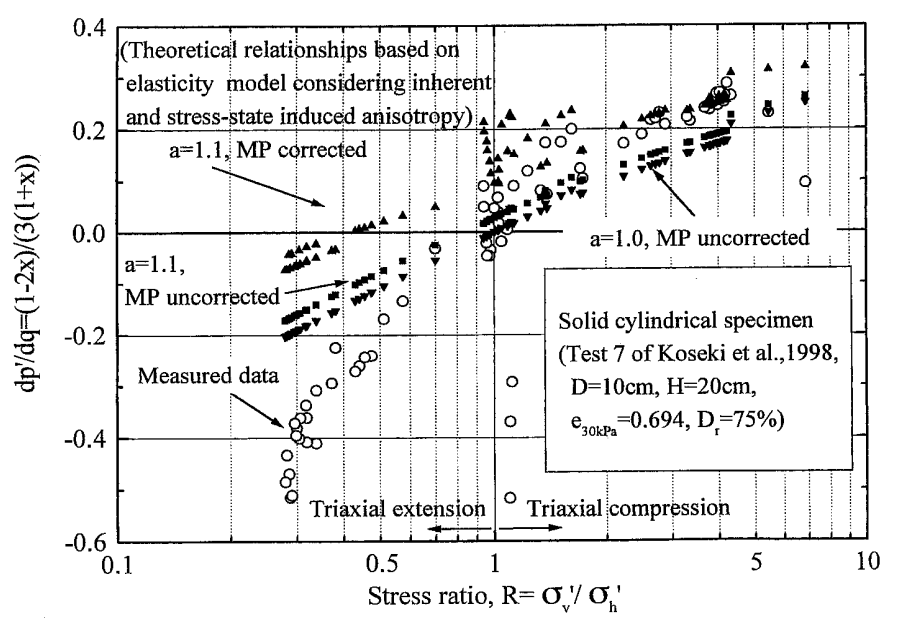

Fig. 19. Direction of effective stress path during undrained small cyclic vertical loading obtained on solid cylindrical specimen (Koseki et al., 1998)

condition the measured value deviated largely from the theoretical one. The latter deviation may be related to the observation that the extent of degradation in the values of $E_{v}$ and $G_{u}$ during liquefaction was larger under triaxial extension condition than under triaxial compression condition (Figs. 14 and 16). As shown in Fig. 19, a similar trend of behavior has been observed in solid cylindrical specimens by Koseki et al..(1998).

It should be noted that values of $d p^{\prime} / d \tau$ measured during undrained small cyclic torsional loading as typically shown in Fig. 5b were always nearly zero. This behavior suggests that dilatancy was not mobilized during small cyclic torsional loading, resulting in almost the same values of $G$ and $G_{u}$ measured during isotropic consolidation (Fig. 10).

\section{CONCLUSIONS}

The results from large amplitude undrained cyclic torsional and triaxial tests on Toyoura sand measuring change of small strain quasi-elastic deformation properties can be summarized as follows.

During isotropic consolidation, the drained and undrained shear moduli were almost the same irrespective of the drainage condition. The difference in the drained and undrained vertical Young's moduli that was measured during isotropic consolidation could be explained by considering inherent and stress state-induced anisotropy in the modeling of quasi-elastic deformation characteristics and by correcting for the effects of membrane penetration. The latter correction was necessary even when the involved strain level was as small as $0.001 \%$.

During the liquefaction process induced by large amplitude undrained cyclic shearing, degradation in the quasielastic deformation properties was observed when compared to those measured during isotropic consolidation. The extent of degradation in the values of the shear modulus and the vertical Young's modulus was generally 
similar in general. Degradation during undrained cyclic torsional shear test was comparable to that under triaxial extension condition during undrained cyclic triaxial shear test, which was larger than that under triaxial compression condition during the latter test. The different extent of damage to the soil structure during liquefaction was suggested to depend on the stress state. Such changes in the quasi-elastic deformation properties should be properly considered in analyzing the liquefaction process of sands based on elasto-plastic modeling.

\section{ACKNOWLEDGEMENTS}

The authors express their highest appreciation to Prof. Fumio Tatsuoka, Department of Civil Engineering, University of Tokyo who suggested the present study and provided the theoretical framework to analyze the experimental results as shown in the Appendix. They also thank Ms. Michie Torimitsu and Mr. Kimitoshi Hayano, IIS, University of Tokyo for their help in conducting the present study.

\section{NOTATION}

$a=$ Parameter representing the degree of inherent anisotropy in Young's modulus

$b=$ Parameter representing the degree of membrane penetration

$D=$ Diameter of solid cylindrical specimen

$D_{i}=$ Inner diameter of hollow cylindrical specimen

$D_{o}=$ Outer diameter of hollow cylindrical specimen

$E_{h}=$ Drained horizontal Young's modulus

$E_{v}=$ Drained vertical Young's modulus

$E_{v, c y c}=$ Drained vertical Young's modulus estimated based on undrained one measured during liquefaction process

$E_{v, i s o}=$ Drained vertical Young's modulus measured during isotropic consolidation

$E_{v u}=$ Undrained vertical Young's modulus

$e_{0}=$ Reference void ratio

$e_{30 \mathrm{kPa}}=$ Void ratio of specimen under isotropic confining stress of 30 $\mathrm{kPa}$

$G=$ Drained shear modulus defined on vertical and horizontal planes

$G_{u}=$ Undrained shear modulus defined on vertical and horizontal planes

$G_{u, c y c}=$ Undrained shear modulus measured during liquefaction process

$G_{u, i s o}=$ Undrained shear modulus measured during isotropic consolidation

$G_{45}=$ Drained shear modulus defined on a plane inclined by 45 degrees from the horizontal plane $\left(=E_{v} / 2\left(1+v_{v h}\right)\right)$

$G_{u 45}=$ Undrained shear modulus defined on a plane inclined by 45 degrees from the horizontal plane $\left(=E_{v u} / 2\left(1+v_{u}\right)\right)$

$H=$ Height of solid/hollow cylindrical specimen

$m=$ Parameter representing the degree of stress state dependency of Young's modulus

$p^{\prime}=$ Effective mean principal stress $\left(=\left(\sigma_{v}^{\prime}+2 \sigma_{h}^{\prime}\right) / 3\right)$

$q=$ Deviator stress $\left(=\sigma_{v}^{\prime}-\sigma_{h}^{\prime}\right)$

$q_{\max }=$ Maximum deviator stress

$R=$ Stress ratio $\left(=\sigma_{v}^{\prime} / \sigma_{h}^{\prime}\right)$

$S L=$ Parameter representing the degree of shear stress level $(=q /$ $\left.q_{\max }\right)$

$x=$ Stress increment ratio $\left(=d \sigma_{h}^{\prime} / d \sigma_{v}^{\prime}\right)$ during small cyclic vertical loading under undrained condition

$\gamma=$ Shear strain mobilized on vertical and horizontal planes

$\varepsilon_{v}=$ Vertical strain $\varepsilon_{v}^{e}=$ Elastic vertical strain

$\varepsilon_{h}^{e}=$ Elastic horizontal strain

$\varepsilon_{\mathrm{MP}}=$ Apparent volmetric strain due to membrane penetration

$v_{v h}, v_{h v}$

$=$ Drained Poisson's ratios defined between vertical and horizontal planes

$v_{u}=$ Undrained Poisson's ratio

$v_{0}=$ Drained Poisson's ratio under a stress state when the material exhibits isotropic behavior

$\sigma_{0}^{\prime}=$ Reference stress

$\sigma_{h}^{\prime}=$ Effective horizontal stress

$\sigma_{m}^{\prime}=$ Effective mean stress $\left(=\left(\sigma_{v}^{\prime}+\sigma_{h}^{\prime}\right) / 2\right)$

$\sigma_{v}^{\prime}=$ Effective vertical stress

$\tau=$ Shear stress applied on vertical and horizontal planes

\section{REFERENCES}

1) Ampadu, S. K. and Tatsuoka, F. (1993): “Effect of setting method on the behaviour of clays in triaxial compression from saturation to undrained shear," Soils and Foundations, Vol. 33, No. 2, pp. 14-34.

2) Goto, S. (1986): "Strength and characteristics of granular materials in triaxial tests," Dr. of Eng. Thesis, Univ. of Tokyo.

3) Hardin, B. O. and Richart, F. E. (1963): "'Elastic wave velocities in granular soils," J. Soil Mech. Found. Div., ASCE, Vol. 89, No. SM1, pp. 33-65.

4) Hoque, E. (1996): "Elastic deformation of sands in triaxial tests," $\mathrm{PhD}$. Thesis, Univ. of Tokyo.

5) Hoque, E. and Tatsuoka, F. (1998): "Anisotropy in elastic deformation of granular materials," Soils and Foundations, Vol. 38, No. 1, pp. 163-179.

6) Koseki, J., Hamaya, S., Tatsuoka, F. and Maeshiro, N. (1998): "Elastoplastic deformation characteristics of Toyoura sand during liquefaction," Geotechnical Engineering and Soil Dynamics III, Geotechnical Special Publication No. 75, ASCE, Vol. 1, pp. 385397.

7) Koseki, J., Sato, T., Maeshiro, N. and Urano, I. (1999a): “Elastic deformation properties of sands containing fines during liquefaction," Physics and Mechanics of Soil Liquefaction, Lade and Yamamuro (eds.), Balkema, pp. 121-132.

8) Santucci de Magistris, F., Koseki, J., Amaya, M., Hamaya, S., Sato, T. and Tatsuoka, F. (1999): "A triaxial testing system to evaluate stress-strain behavior of soils for wide range of strain and strain rate," Geotech. Testing J., Vol. 22, pp. 44-60.

9) Tanizawa, F., Teachavorasinskun, S., Yamaguchi, J., Sueoka, T. and Goto, S. (1994): "Measurement of shear wave velocity of sand before liquefaction and during cyclic mobility," Pre-failure Deformation of Geomaterials, Shibuya, Mitachi and Miura (eds.), Balkema, Vol. 1, pp. 63-68.

10) Tatsuoka, F. and Kohata, Y. (1995): "Stiffness of hard soils and soft rocks in engineering applications," Pre-failure Deformation of Geomaterials, Shibuya, Mitachi and Miura (eds.), Balkema, Vol. 2, pp. 947-1043.

11) Tatsuoka, F., Jardine, R. J., Lo Presti, D., Di Benedetto, H. and Kodaka, T. (1999): "Characterising the pre-failure deformation properties of geomaterials," Proc. of 14th Int. Conf. on SMFE, Hamburg/6-12 September 1997, Vol. 4, pp. 2129-2164.

12) Yamashita, S., Toki, S. and Suzuki, T. (1996): "Effects of membrane penetration on modulus and Poisson's ratio for undrained cyclic triaxial conditions," Soils and Foundations, Vol. 36, No. 4, pp. 127-133.

\section{APPENDIX: MODELING OF ELASTIC DEFORMA- TION PROPERTIES}

The cross-anisotropic elastic formulation employed to analyze the present results is briefly explained below; it is a slightly modified version of the one employed by 
Koseki et al. (1998). Effects of the membrane penetration on hollow cylindrical specimens are newly cosidered.

It has been experimentally reported by Hoque and Tatsuoka (1998) that the quasi-elastic Young's modulus of granular materials is basically a function of the effective normal stress in the direction of the major principal strain increment. Therefore, the drained vertical and horizontal Young's moduli, denoted as $E_{v}$ and $E_{h}$, respectively, were formulated by Eqs. (1) and (2), as proposed by Tatsuoka and Kohata (1995):

$$
\begin{aligned}
& E_{v}=E_{v 0}\left(\sigma_{v}^{\prime} / \sigma_{0}^{\prime}\right)^{m} \cdot f(e) / f\left(e_{0}\right) \\
& E_{h}=E_{h 0}\left(\sigma_{h}^{\prime} / \sigma_{0}^{\prime}\right)^{m} \cdot f(e) / f\left(e_{0}\right)
\end{aligned}
$$

where $\sigma_{0}^{\prime}$ and $e_{0}$ are the reference stress and void ratio, and $f(e)=(2.17-e)^{2} /(1+e)$ is the void ratio function to account for the effects of void ratio changes (Hardin and Richart, 1963). These properties result in stress state-induced anisotropy in the quasi-elastic deformation characteristics (Tatsuoka and Kohata, 1995).

By assuming a symmetricity for the elastic compliance matrix, the drained Poisson's ratios are assumed to be basically dependent on the current stress ratio $R=\sigma_{v}^{\prime} / \sigma_{h}^{\prime}$ as formulated by:

$$
\begin{aligned}
& v_{v h}=v_{0} \sqrt{a} \cdot R^{m / 2}, \\
& v_{h v}=v_{0}(1 / \sqrt{a}) \cdot R^{-m / 2}
\end{aligned}
$$

where $a$ is a parameter representing the degree of inherent anisotropy $\left(a \equiv E_{v 0} / E_{h 0}\right)$, and $v_{0}$ is the value of $v_{v h}=v_{h v}$ when $R=a^{-1 / m}$. In the present study, reference values of $a$ and $v_{0}$ were set to 1.1 and 0.15 , respectively, based on the results by Hoque and Tatsuoka (1998). Further, the Poisson's ratio defined on two orthogonal horizontal planes $v_{h h}$ was assumed constant and equal to $v_{0}$.

By using Eqs. (1) to (4), the elastic normal strain increments $d \varepsilon_{v}^{e}$ and $d \varepsilon_{h}^{e}$ in the vertical and horizontal directions, caused by effective stress increments $d \sigma_{v}^{\prime}$ and $d \sigma_{h}^{\prime}$, can be evaluated as:

$$
\begin{aligned}
& d \varepsilon_{v}^{e}=\frac{1}{E_{v}} d \sigma_{v}^{\prime}+2 \frac{v_{h v}}{E_{h}} d \sigma_{h}^{\prime} \\
& d \varepsilon_{h}^{e}=\frac{1+v_{0}}{E_{h}} d \sigma_{h}^{\prime}+\frac{v_{v h}}{E_{v}} d \sigma_{v}^{\prime} .
\end{aligned}
$$

In some cases, effects of membrane penetration were considered by formulating the apparent volumetric strain increment $d \varepsilon_{\mathrm{MP}}$ due to membrane penetration by:

$$
d \varepsilon_{\mathrm{MP}}=\frac{4 b}{\sigma_{h}^{\prime} \cdot\left(D_{o}-D_{i}\right)} d \sigma_{h}^{\prime}
$$

where $D_{o}$ and $D_{i}$ are the outer and the inner diameters of the specimen in $\mathrm{cm}$, and $b$ is a parameter that was experimentally obtained by Goto (1986) to be $1.7 \times 10^{-3} /$ $\log _{\mathrm{e}} 10$ for Toyoura sand.

Based on these assumptions, the theoretical relationship between the undrained and drained vertical Young's moduli, denoted as $E_{v u}$ and $E_{v}$, respectively, at the same stress state was obtained by Tatsuoka et al. (1999) as:

$$
E_{v}=E_{v u} \frac{1+2\left(a R^{m}\right)^{0.5} v_{0} x}{1+x}
$$

where $x$ is the stress increment ratio during small cyclic vertical loading under undrained condition given by:

$$
\begin{aligned}
x & =-\left(\frac{d \sigma_{h}^{\prime}}{d \sigma_{v}^{\prime}}\right) \\
& =\frac{1-2\left(a R^{m}\right)^{0.5} v_{0}}{2 a R^{m}\left[1-v_{0}-\left(a R^{m}\right)^{-0.5} v_{0}+2\left(b E_{h}\right) /\left(\sigma_{h}^{\prime}\left(D_{o}-D_{i}\right)\right)\right]} .
\end{aligned}
$$

The ratio $d p^{\prime} / d q$, which denotes the average direction of the effective stress path measured during undrained small cyclic vertical loading, as typically shown in Fig. $6 \mathrm{~b}$, can also be predicted as a unique function of $x$ by:

$$
\frac{d p^{\prime}}{d q}=\frac{1-2 x}{3(1+x)} \text {. }
$$

